\title{
Entirely Passive Remote Node Design And System Architecture For Bus Topology Based 80Gbps Symmetrical NG-PON2
}

Ramandeep Kaur ( $\square$ ramandeep_ece@pbi.ac.in )

Punjabi University Patiala

Simranjit Singh Tiwana

Punjabi University Patiala

Rajandeep Singh

Guru Nanak Dev University

Simranjit Singh

Punjabi University Patiala

\section{Research Article}

Keywords: NG-PON2, Remote Node, Bus Topology.

Posted Date: September 1st, 2021

DOI: https://doi.org/10.21203/rs.3.rs-625511/v1

License: (9) This work is licensed under a Creative Commons Attribution 4.0 International License. Read Full License 


\section{Abstract}

The next generation passive optical network stage 2 (NG-PON2) is a broadcast network in which a large number of optical network units (ONUs) can be served using various network topologies. In this paper, a purely passive remote node (RN) design based on fiber bragg grating (FBG) is presented for the bus topology of a high split NG-PON2 system. The performance of the proposed node has been analysed for a symmetric 80 Gbps NG-PON2 system serving 1024 ONUs in terms of bit error rate (BER) and optical signal to noise ratio (OSNR). The working of the proposed node has been explained with the optical frequency spectrums for downstream and upstream signals. The observed OSNR levels for the ONUs operating at the $1^{\text {st }} \mathrm{RN}$ is $84.8743 \mathrm{~dB}$ which decreases to $75.7973 \mathrm{~dB}$ for the ONUs connected to the $8^{\text {th }}$ RN. The BER level $<10^{-9}$ for both upstream and downstream confirms the correct working of the proposed node in the NG-PON2 system.

\section{Introduction}

A passive optical network (PON) is a fiber to the home (FTTH) point to a multipoint network that provides high data rate service to end-users [1], [2]. The optical distribution network (ODN) in the PON consists of passive components like optical power splitters, optical fiber, couplers, etc.[3]. According to the ITU-T standards, NG-PON2 technology should outperform existing PON technologies in ODN compatibility, bandwidth, capacity, and cost-efficiency [4]. As per the G.989.2 recommendation of ITU-T, time and wavelength division multiplexing PON (TWDM-PON) is the best hybrid multiplexed technique for NGPON2. TWDM utilizes the bandwidth of optical fiber efficiently. The NG-PON2 is a broadcast network, and a large number of ONUs can be served using various network topologies. These topologies are the arrangement or mapping of the links, nodes, etc. of a network. The operational and maintenance cost depends on the network topology, so for every requirements there exists a most suitable topology [5].

J. Prat et. al proposed an architecture and node design for the hybrid operation of the ring-tree wavelength division multiplexing/time division multiplexing passive optical network (WDM-TDM-PON). In their work, they used optical add-drop multiplexers (OADMs) for dropping the downstream wavelength and adding the upstream wavelengths. They utilized WDM for the ring implementation and TDM in the star topology [6]. P. Lafata et. al proposed the use of a secondary optical line terminal (OLT) in a dual fiber ring topology system. Although the proposed ring-based architecture protects in case of fiber cut or equipment malfunction. However, the cost involved in keeping and additional OLT and dual fiber is quite high [7].

B. Chen et. al. also proposed a similar approach of using ring topology. Their method was based on single fiber ring topology which reduces the cost as compared to dual fiber ring. However, they used active components in the remote node for the switching function which is undesirable [8]. Rafael Sánchez et. al compared Gigabit passive optical network (GPON), 10G-PON (XG-PON), WDM-PON, and TWDM-PON for provisioning $1 \mathrm{Gbps}$ symmetrical data rate service to the end-users. They found that for a green mile solution provisioning up to 5000 users, all these technologies are capable. However, as the number of 
users and their activity increases, only TWDM based optical system is capable enough for guaranteed 1 Gbps symmetrical access [9].

L. Pavel et. al used the dual OLT scheme to provide services to the ONU from both directions (Clockwise direction and Anti-clockwise direction) for bus and ring topology. With this approach the ONUs can easily be switched between OLTs by adapting the transmission direction in case of fiber failure. The data rates considered in this work were conforming to GPON norms. They used dual fiber in their system for link protection. But there is a limitation, both OLTs transmit data at the same time for both directions. Because of that the signals coming from OLT1 interfere with signals coming from OLT2 and vice versa [10]. S. M. Idrus et. al experimentally investigated the $25 \mathrm{Gbps}$ NG-PON system's performance for a $25 \mathrm{~km}$ reach by employing a differential phase-shift keying (DPSK) signal at downstream transmission and its conversion to optical duobinary modulation format at the ONU receiver. The receiver sensitivity of -29 $\mathrm{dBm}$ was observed for BER less than $10^{-5}$ with a 1:64 split ratio [11].

A low-cost 40 Gbps TWDM PON was investigated by Bart Moeneclaey et. al using electrical duobinary modulation (EDM) format at the downstream transmission. They achieved a power budget of $23.6 \mathrm{~dB}$ with forward error correction (FEC) and BER level of $10^{-3}$ with a $20 \mathrm{~km}$ system reach [12]. Many researchers have analysed the performance of PON for various network topologies. Sanjeev Dewra et.al have investigated the performance of the system by deploying different optical network topologies in the presence of a hybrid optical amplifier. They reported that bus topology supports 18 nodes for a minimum signal input power of $-20 \mathrm{dBm}$, ring topology supports 30 nodes for $-30 \mathrm{dBm}$ input power at $10 \mathrm{Gbps}$ data rate with $30 \mathrm{~km}$ reach between successive nodes in the presence of hybrid amplifier. However, they found in hybrid topology that the number of nodes supported for bus topology is 6 and for the ring, it is 10 at $-20 \mathrm{dBm}$ signal input power [13].

Chung-Yi Li et. al proposed a novel tree-based add/drop multiplexer (TOADM) for TWDM NG-PON2. They used two four-port optical circulators (OCs), one three-port OC, and two FBGs passive components to place at any selected location along with transmission fiber to multiplex and de-multiplex optical wavelengths. Through experimental results, they observed that the insertion loss of the proposed device is less than a $1 \times 2$ optical splitter in downstream and upstream directions [14]. From the literature review, it is observed that the selection of network topology plays an important role in the broadcast access network. Also, the previous works are limited to low data rate and fewer users. NG-PON2 network can extend the network capacity to $40 \mathrm{Gbps}$ or $80 \mathrm{Gbps}$ by employing multiple optical carriers and the TWDM concept [15].

In our previous work, we have analysed the feasibility of symmetric $80 \mathrm{Gbps}$ NG-PON architecture. The analysed TWDM based architecture was based on the star topology where 64 ONUs were connected to OLT for symmetrical data rates. From the results, it has been observed that the presented system works well up to $65 \mathrm{~km}$ system length [16]. In our other previous work, the performance of star topology based NG-PON2 high split for 80 Gbps data rate with duobinary modulation format and with avalanche photodiode (APD) receiver was achieved [17]. In this paper, we are proposing the bus topology-based 
architecture for 80Gbps NG-PON2 with 1024 users. To make ODN entirely passive, an RN is designed based on FBG which reflects a portion of the wavelength band out of the incoming signal and it does not affect other wavelengths. In the proposed RN the FBG is used to separate upstream wavelengths from the downstream wavelengths to avoid crosstalk. The paper is organised into four sections. The introduction and related literature are presented in the first section. The simulation architecture of the bus topologybased NG-PON2 system with the proposed node design is described in section two. The obtained results are discussed in section three. In the section four the conclusions from the result are made and at the end of the paper cited references are listed.

\section{li. Simulation Architecture Of 80gbps Ng-pon2 With Bus Topology}

In the present work, the proposed RN design and the 80 Gbps symmetrical NG-PON2 network provisioning 1024 ONUs is simulated in the Optisystem v.13 software. The simulation setup is shown in figure 1 . The wavelength assignment scheme is used as per the ITU-T recommendations for NG-PON2 [5]. Eight wavelengths starting from $1596 \mathrm{~nm}$ with $0.8 \mathrm{~nm}$ channel spacing are multiplexed at the central office (CO) for downstream. For the downstream signals labels from $\lambda_{1}$ to $\lambda_{8}$ are used. The $\lambda_{1}$ is $1596 \mathrm{~nm}$ and the downstream wavelength assigned to the $\mathrm{n}^{\text {th }} \mathrm{RN}$ can be calculated by the following equation.

$$
\lambda_{\mathrm{n}}=\lambda_{1}+(\mathrm{n}-1) \times 0.8 \mathrm{~nm}
$$

Each wavelength carries a $10 \mathrm{Gbps}$ data rate that makes the system capable of $80 \mathrm{Gbps}$ data rate service. The multiplexed data is transmitted over single-mode fiber (SMF). PON is a point to the multipoint network so the data is broadcast using a bus topology near the user premises. In this topology, all ONUs are connected to a common transmission fiber. The data to the dedicated groups of ONUs is transmitted in the network as per the assigned wavelengths. In this way, the data transmission between every ONU and OLT takes place over the same primary fiber. For upstream transmission, eight wavelengths $\left(\lambda_{9}-\lambda_{16}\right)$ starting from $1524 \mathrm{~nm}$ to $1529.6 \mathrm{~nm}$ with $0.8 \mathrm{~nm}$ channel spacing are used in the system. The first upstream wavelength $\lambda_{9}$ of $1524 \mathrm{~nm}$ is assigned for upstream from the ONUs of RN1. The dedicated upstream wavelength for the ONUs operating at the $\mathrm{n}^{\text {th }} \mathrm{RN}$ can be calculated by the following generalized equation.

$$
\lambda_{\mathrm{n}+8}=\lambda_{9}+(\mathrm{n}-1) \times 0.8 \mathrm{~nm}
$$

In the bus topology, RNs connect the clusters of ONUs with the OLT. The RN should be designed in such a way that it should allow simultaneous flow of downstream data to all ONUs and flow of upstream data from the node under consideration and all other nodes can pass through it towards OLT.

Each upstream wavelength carries a $10 \mathrm{Gbps}$ data rate similar to the downstream. Each ONU can transmit its upstream data as per the assigned time slot, for this TWDM scheme is used. Equal time slots are allocated to each ONU. Since the NG-PON supports TWDM, The ONU connected to a common RN 
transmit their upstream data on a common upstream wavelength but in different time slots. Figure 2 shows how the upstream is assigned to a cluster of ONUs with the dedicated time slots. The dynamic $Y$ switch 1 and dynamic $Y$ switch 2 marks the start time and end time to the assigned slot dedicated to $1^{\text {st }}$ ONU. A parameter named "Timeslot" is defined to allow the static time slot to each ONU. Considering the complexity of the simulation, the "Timeslot" parameter values from 0 to 7 are assigned to eight ONUs of every RN. "Timeslot" value is 0 for the first ONU; it is 1 for the second ONU, and so on it is 7 for the $8^{\text {th }}$ $\mathrm{ONU}$, other ONUs are assumed to be in off state. The following equations mark the start time and end time of the slot allocated to any ONU.

$$
\text { Start time }=\text { Time Slot } \times\left(\frac{1}{\text { Bit rate }}\right) \times \frac{\text { Sequence length }}{8}
$$

$$
\text { End time }=\text { Time Slot } \times\left(\frac{1}{\text { Bit rate }}\right) \times \frac{\text { Sequence length }}{8}+\frac{\text { Time window }}{8}
$$

For the simulations, the "Bit rate" of $10 \mathrm{Gbps}$, the sequence length of 256 bits, and a time window of $56.6 \times 10^{-9}$ seconds is set. The combined data frame is obtained after combining the power from every input to the power combiner.

Then passive power combiner combines the upstream data coming from each group of ONUs. The combined data is transmitted towards OLT through AWG over the same SMF that was carrying the downstream traffic. At the OLT receiver, all upstream wavelengths are de-multiplexed and received. The correct reception at Rx1 confirms the successful reception of upstream data at OLT sent by ONUs connected to RN1. Similarly, the Rx8 receives the upstream of all ONUs sharing upstream wavelength dedicated to RN8. For the amplification of downstream signals, a Raman pump of $1535 \mathrm{~nm}$ is also sent from the OLT to compensate for the loss. The simulation parameters are listed in table 1.

Table1: Simulation Parameters for Symmetric 80 Gbps TWDM PON 


\begin{tabular}{|ll|}
\hline NAME & VALUE \\
\hline SMF1 & $20 \mathrm{~km}$ \\
\hline SMF2- SMF8 & $1 \mathrm{~km}$ \\
\hline Total Bit rate (Upstream/Downstream) & $80 \mathrm{Gbps}$ \\
\hline Split per wavelength & 128 \\
\hline Total Number of ONUs & 1024 \\
\hline Number of wavelengths (Downstream) & $8(1524-1529.6) \mathrm{nm}$ \\
\hline Number of wavelengths (Upstream) & $8(1596-1601.6) \mathrm{nm}$ \\
\hline Channel spacing (Upstream/Downstream) & $0.8 \mathrm{~nm}$ \\
\hline
\end{tabular}

\section{lii. Rn Design Using Fbg For 80gbps Twdm Based Ng-pon2 With Bus Topology}

In this work, RN design has been proposed for high split NG-PON2 downstream transmission using bus topology which also supports multi-wavelength upstream. We have deployed eight wavelengths for downstream transmission in this work, so a fixed downstream wavelength is allocated to each RN. The structure of $n^{\text {th }}$ generalized $\mathrm{RN}_{\mathrm{n}}$ is presented in figure 3 to explain how downstream and upstream wavelengths pass through the node, here $\mathrm{n}$ is the node number which is 1 to 8 in this case. The downstream wavelengths from $\lambda_{n}$ to $\lambda_{8}$ enter the $n^{\text {th }} R N$ from the left port The $\lambda_{n}$ is dropped with the FBG tuned to reflect $\lambda_{n}$ out of these wavelengths. The downstream data stream is provided to every ONU connected with $n^{\text {th }} \mathrm{RN}$ with the reflected wavelength $\lambda_{\mathrm{n}}$. The remaining downstream wavelengths from $\lambda_{n+1}$ to $\lambda_{8}$ pass through the FBG and are routed to the $\mathrm{RN}_{\mathrm{n}+1}$. Similarly, the upstream data of all ONUs connected to $n^{\text {th }} R N$ is generated at wavelength. The upstream wavelength $\lambda_{n+8}$ of $n^{\text {th }} R N$ gets coupled with $\lambda_{n+9}$ to $\lambda_{16}$ upstream wavelengths which are coming from $R N_{n+1}$. All these wavelengths from $\lambda_{n+8}$ to $\lambda_{16}$ are propagated towards the $\mathrm{RN}_{\mathrm{n}-1}$. The $\mathrm{RN}_{\mathrm{n}-1}$ will further add its allocated upstream wavelength, and an upstream path is established between every ONU and OLT. In this way, the proposed RN can connect downstream and upstream transmission link between the ONUs and OLT. The proposed RN design is used in the simulation architecture shown in figure 1. To verify the operation of the proposed RN, the optical spectrum diagrams have been obtained.

The obtained spectrum of all transmitted downstream signals from the OLT is shown in figure 4. It can be seen from the spectrum that eight downstream wavelengths starting from $1596 \mathrm{~nm}$ with a channel spacing of $0.8 \mathrm{~nm}$ have the same optical power. This signal propagates through the optical fiber and 
reaches $\mathrm{RN} 1$, the FBG in the first $\mathrm{RN}$ is tuned to reflect $1596 \mathrm{~nm}$ downstream wavelength. The reflected $\lambda_{1}=1596 \mathrm{~nm}$ signal is received by the cluster of ONUs operating on the RN1.

The observed spectrum of the received wavelength at the ONU connected to RN1 is shown in figure 5. The peak of the $1596 \mathrm{~nm}$ signal justifies the reception of the correct assigned wavelength. Although the other downstream signals are also present in the reflected spectrum. But their power is relatively lower than the $1596 \mathrm{~nm}$.

After reflection of $\lambda_{1}$ at RN1, the remaining downstream wavelengths get transmitted to RN2. The second RN is accepting the unreflected part of the signal crossed through RN1. The spectrum of signal reached RN2 is shown in figure 6. From the spectrum, it can be observed that the signal level of $1596 \mathrm{~nm}$ allocated to RN1 is much attenuated as compared to other signal wavelengths and $\lambda_{2}-\lambda_{8}$ wavelengths are received in RN2. It can be concluded from figure 4, figure 5 and figure 6 that the wavelength assigned to the particular RN is being correctly received at the ONUs and the remaining wavelengths are passed on to the subsequent RNs.

To further explain the working of the proposed design we have chosen to show the optical spectrum for first, fifth and eighth RN. The spectrum reaching the RN5 is shown in figure 7, it is evident that the first four RNs have dropped their assigned wavelengths and the wavelengths assigned to the RN5-RN8 are still available. The fifth RN is tuned to drop $\lambda_{5}$ wavelength of $1599.2 \mathrm{~nm}$. The operation of the RN5 is similar to the operation of RN1 which is explained above. The received downstream spectrum at the ONU connected to RN5 is shown in figure 8.

After the reflection of $1599.2 \mathrm{~nm}$ at RN5, the spectrum should contain the remaining downstream wavelengths assigned to RN6, RN7 and RN8 which are $1600 \mathrm{~nm}, 1600.8 \mathrm{~nm}$ and $1601.6 \mathrm{~nm}$. The spectrum at the output of RN5 is shown in figure 9. It can be seen that the wavelengths assigned to the first 5 nodes are much attenuated, and wavelengths assigned to RN6, RN7 and RN8 are still having higher power. This way a downstream wavelength is dropped at each $\mathrm{RN}$ and connectivity of all the eight RNs to the OLT is established. The signal received at the ONU connected to the eight RN is shown in figure 10.

Eight upstream wavelengths starting from $1524 \mathrm{~nm}$ with $0.8 \mathrm{~nm}$ channel spacing have been assigned to eight sets of ONUs connected to eighth RNs. The upstream wavelengths are chosen as per the dedicated wavelength plan by ITU-T for NGPON-2 [5]. Since the notation of $\lambda_{1}-\lambda_{8}$ is used for downstream signals, the names $\lambda_{9}-\lambda_{16}$ are given to the upstream wavelengths. During upstream each cluster of ONU connected to an RN generates an upstream signal at the wavelength allocated to that $R N$. The $R N_{n+1}$ send the upstream signal containing $\lambda_{n+9}-\lambda_{16}$ to the $R N_{n}$ node. The $R N_{n}$ adds its upstream wavelength $\lambda_{n+8}$ generated by the ONUs connected to it. And thus the $R N_{n}$ sends the $\lambda_{n+8}-\lambda_{16}$ upstream wavelengths towards $\mathrm{RN}_{\mathrm{n}-1}$. This way the OLT receives all the upstream wavelengths from $\lambda_{9}-\lambda_{16}$. The upstream spectrum diagrams of signals received by the RN5 from RN6 and the upstream signal transmitted by RN5 to RN4 are shown in figure 11 and figure 12. Similarly, the Upstream spectrum containing data of ONUs of 
all RNs is shown in figure 13. This signal is demultiplexed at the OLT and the BER has been evaluated. There are some four wave mixing signals which can be seen in figure 13. However, their power level is very small, so they do not have any effect on the system performance.

\section{Iv. Result And Discussion}

The performance of a system has been analysed by observing the BER and OSNR for each RN. As the RN1 is closest to the OLT, it is expected that the performance will degrade as we will move from RN1 towards RN8 to the OLT. For this, it is necessary to assess the entire system's performance (for all RNs). The observed BER for all the RNs is plotted in figure 14.

The graph shows that the RN1 which operates at $1596 \mathrm{~nm}$ wavelength performs best and the BER increases for the subsequent RNs as we move away from OLT. The BER below $10^{-9}$ level for all the wavelengths is suggesting that the BER for downstream at all the 1024 ONUs is under acceptable limits. The received power at the RN1 is $-22 \mathrm{~dB}$ and the power decreases as the distance of RN increases from OLT. The received power at the $8^{\text {th }} \mathrm{RN}$ decreases to $-28 \mathrm{~dB}$. This is the reason why the BER comes better for the $1^{\text {st }} \mathrm{RN}$ and the BER increases for every next RN.

The eye diagrams are also considered in this analysis, the eye diagrams for the ONUs connected to various RNs are shown in figure 15 . From the eye diagrams, it can be observed that the eye degradation is there if we move from RN1 towards RN8.

The degradation of the signal quality at the ONUs connected to all the RNs has been measured in form of OSNR of the signal received. The variation of OSNR for the ONUs connected to various RNs is shown in figure 16. The OSNR decreases as the distance between OLT and RN increases. The OSNR at the RN1 is highest and as the signal propagates through various RNs and fibers the OSNR decreases. The increase in BER which is shown in figure 14 is the result of this OSNR decrease as we move towards the farthest RNs. The OSNR level of $84.8743 \mathrm{~dB}$ was observed at the ONU connected to the RN1, it decreases to $75.7973 \mathrm{~dB}$ at the ONU connected to RN8.

The system performance is also investigated for the upstream transmission. The wavelengths are according to the NG-PON2 specifications. The wavelength range used for upstream is from $1524 \mathrm{~nm}$ to $1529.6 \mathrm{~nm}$ with $0.8 \mathrm{~nm}$ channel spacing. TWDM technique is used in upstream transmission. As each group of ONUs are sharing the same wavelength, each ONU transmits their data using the TDM technique.

As it can be seen from figure 13 the power of the upstream signal wavelength $\lambda_{9}=1524 \mathrm{~nm}$ is highest as it is nearest to the OLT, and the upstream wavelengths of other RNs are crossing fiber segments and nodes therefore a power reduction is there. The effect of the decrease of the power of the upstream signal coming from farthest ONUs can be seen from figure 20 which is showing the BER observed at the OLT. The $1524 \mathrm{~nm}$ upstream wavelength (from RN1) is providing a BER $<10^{-35}$. Whereas, the BER increases as 
the distance of RN from OLT increases. The BER of the upstream signal $\lambda_{16}(1529.6 \mathrm{~nm})$ sent by RN8 is barely acceptable with BER of the order of $10^{-9}$. This problem for high BER in case of farthest RNs can be eliminated by using the higher upstream power of the ONUs or by providing amplification to the upstream signals.

\section{Conclusion}

In this paper, an RN design based on FBG has been proposed for the bus topology of the NG-PON2 system. The performance of NG-PON2 is investigated with the proposed RN design. The BER for downstream transmission is observed below $10^{-9}$ level for all RNs. It suggests that the BER values for all 1024 ONUs operating in the system are under acceptable limits. A -22 dB power is received at the ONUs working on RN1 and it is observed that the signal power decreases as the distance between RN from OLT increases. The received power at the ONUs of $8^{\text {th }} \mathrm{RN}$ decreases to $-28 \mathrm{~dB}$. The variation of OSNR for the ONUs connected to every RNs is also obtained. The OSNR decreases as the distance between OLT and $\mathrm{RN}$ increases. The observed OSNR levels for the ONUs operating at the $1^{\text {st }} \mathrm{RN}$ is $84.8743 \mathrm{~dB}$ which decreases to $75.7973 \mathrm{~dB}$ for the ONUs connected to the $8^{\text {th }} \mathrm{RN}$. The BER for all the upstream wavelengths

is found acceptable (below $10^{-9}$ level). For the upstream from the first RN, BER observed is $<10^{-35}$. The BER for upstream increases as the distance of RN from the OLT increases. The BER of the upstream signal $\lambda_{16}$ sent by RN8 is barely acceptable with a BER value of the order of $10^{-9}$. The acceptable BER $\left(<10^{-9}\right)$ for both upstream and downstream validates the correct operation of the proposed remote node in 80 Gbps symmetrical NG-PON2.

\section{Declarations}

\section{Acknowledgements:}

The authors wish to convey thanks to the Ministry of Electronics and Information Technology, Government of India for providing assistance through Visvesvaraya Ph.D. Scheme for Electronics \& IT.

\section{References}

[1] A. Usman, N. Zulkifli, M. R. Salim, K. Khairi, and A. I. Azmi, "Optical link monitoring in fibre-to-the-x passive optical network (FTTx PON): A comprehensive survey," Opt. Switch. Netw., vol. 39, p. 100596, 2020.

[2] A. Usman, N. Zulkifli, M. R. Salim, K. Khairi, and A. I. Azmi, "Optical link monitoring in fibre-to-the-x passive optical network (FTTx PON): A comprehensive survey," Opt. Switch. Netw., vol. 39, p. 100596, 2020. 
[3] D. Nesset, “PON Roadmap [ Invited ],” J. Opt. Commun. Netw., vol. 9, no. 1, pp. 71-76, 2017.

[4] R. Kaur and S. Singh, "Polarization multiplexing and hybrid modulation based bandwidth efficient NG-PON2 coexisting GPON and XG-PON,” J. Opt. Technol., vol. 88, no. 4, pp. 196-201, 2021.

[5] ITU-T, "40-Gigabit-capable passive optical networks 2 (NG-PON2): Physical media dependent (PMD) layer specification," ITU-T Recomm. G.989.2, vol. 2, 2014.

[6] J. Prat, J. Lazaro, P. Chanclou, and S. Cascelli, "Passive OADM Network Element for Hybrid RingTree WDM / TDM-PON," in 35th European Conference on Optical Communication, Vienna, Austria, pp. 2324, 20-24 September, 2009.

[7] P. Lafata and J. Vodrazka, "Simulation of ring-based passive optical network and its experimental verification," Elektron. ir Elektrotechnika, vol. 19, no. 5, pp. 93-98, 2013.

[8] B. Chen and C. Gan, "Novel architecture of WDM-PON based on single-fiber ring topology featuring protection and dynamic wavelength assignment," Opt. Int. J. Light Electron Opt., vol. 124, no. 3, pp. 234237, 2013.

[9] R. Sánchez, J. A. Hernández, J. M. Garciá, and D. Larrabeiti, "Provisioning 1 Gb/s symmetrical services with next-generation passive optical network technologies," IEEE Commun. Mag., vol. 54, no. 2, pp. 72-77, 2016.

[10] L. Pavel, "Novel protection strategies for passive optical networks based on ring and bus topologies," Trans. Emerg. Telecommun. Technol., vol. 26, no. 9, pp. 1131-1153, Sep. 2015.

[11] S. M. Idrus, S. U. Rehman, N. Zulkifli, F. Iqbal, and A. Kanno, "Demonstration of Receiver Generated Optical Duobinary and VSB-NRZ for Next-Generation PON," IEEE 7th Int. Conf. Photonics (ICP), Kuah, Malaysia, pp. 1-3, 9-11 April , 2018.

[12] B. Moeneclaey et al., "40-Gb/s TDM-PON Downstream Link With Low-Cost EML Transmitter and APD-Based Electrical Duobinary Receiver," J. Light. Technol., vol. 35, no. 4, pp. 1083-1089, 2017.

[13] S. Dewra and R. S. Kaler, "Performance analysis of optical network topologies in the presence of hybrid optical amplifier," Optoelectron. Adv. Mater. Rapid Commun., vol. 11, no. 1-2, pp. 54-58, 2017.

[14] C. Y. Li, C. H. Chang, Z. G. Lin, and Z. Y. Cheng, “Optical add/drop multiplexer for tree-based passive optical networks," Opt. Fiber Technol., vol. 54, pp. 102121 (1-4), Jan. 2020.

[15] ITU-T, "40-Gigabit-capable passive optical networks (NG-PON2): Transmission convergence layer specification," ITU-T Recomm. G989.3, vol. 3, 2016.

[16] R. Kaur and S. Singh, "A Time and Wavelength Division Multiplexing based Next Generation Passive Optical Networks Provisioning 80Gbps Symmetrical Access Rate," in International Conference on Recent 
[17] R. Kaur, S. Singh, and M. L. Singh, "Power budget calculations of high-speed twdm based nextgeneration passive optical network for different data types," Optoelectron. Adv. Mater. Rapid Commun., vol. 15 , no. 1-2, pp. 39-48, 2021.

\section{Figures}

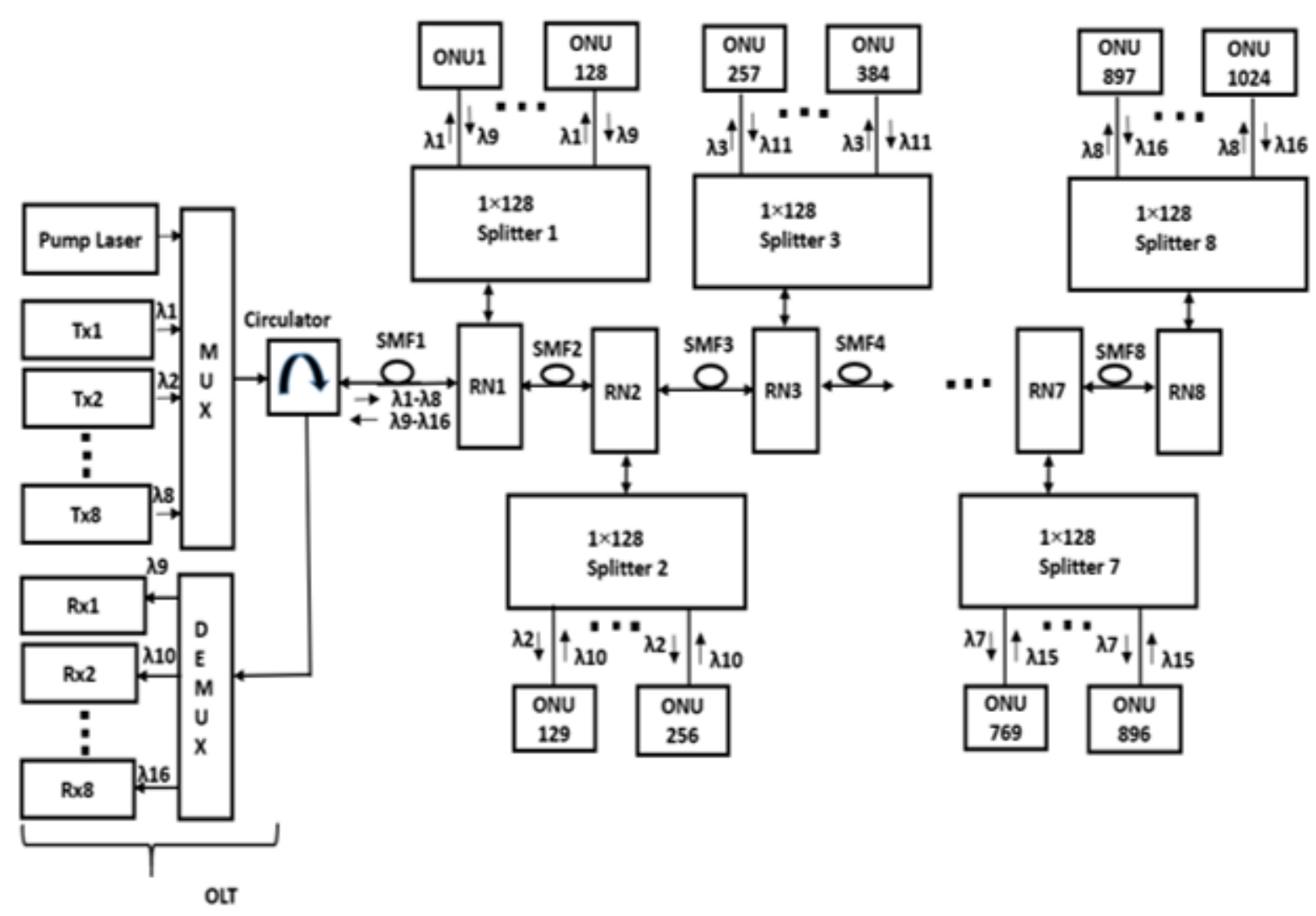

Figure 1

Simulation Architecture of 80 Gbps NG-PON2 with Bus Topology 


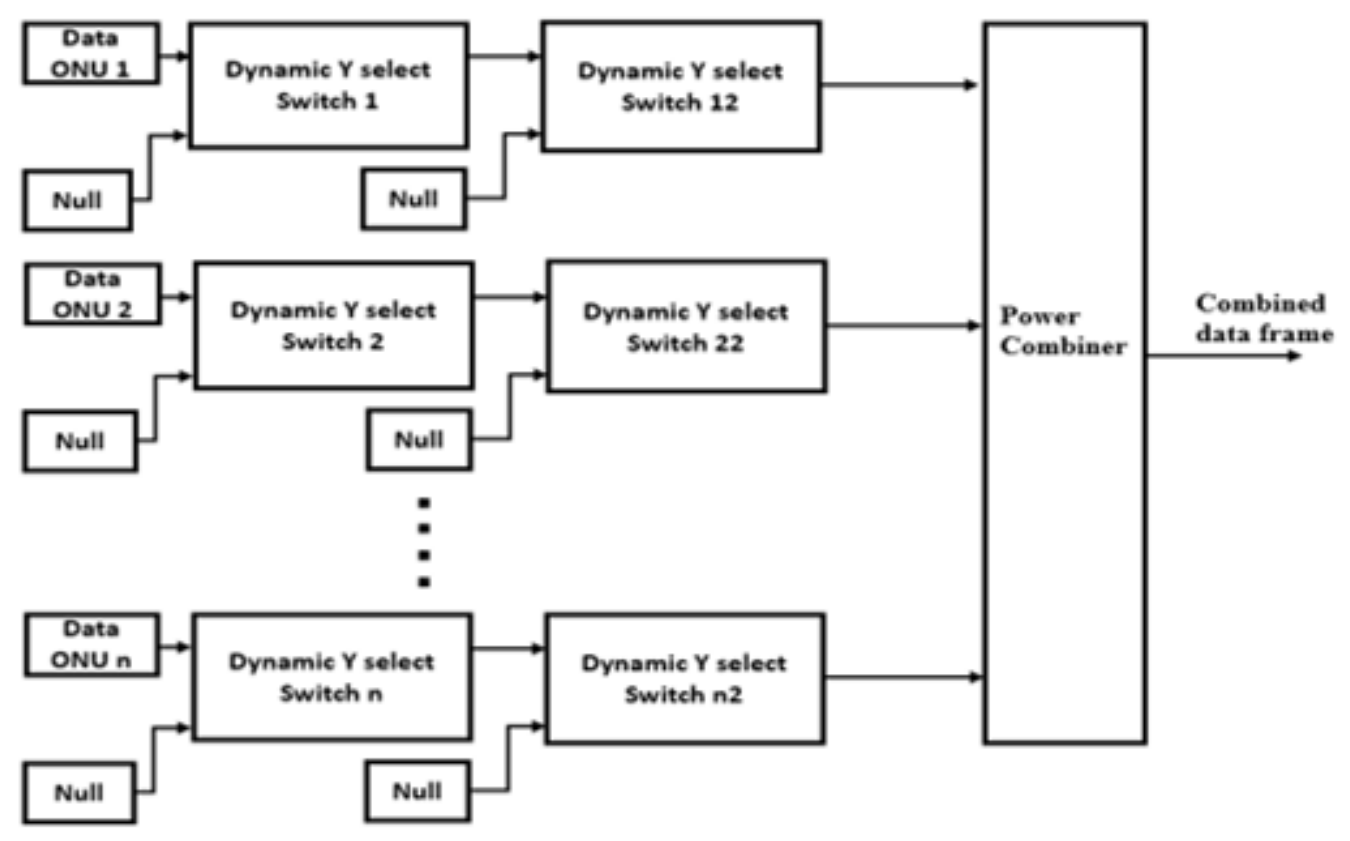

Figure 2

Combined Data Frame Formation from Individual data of ONUs. 


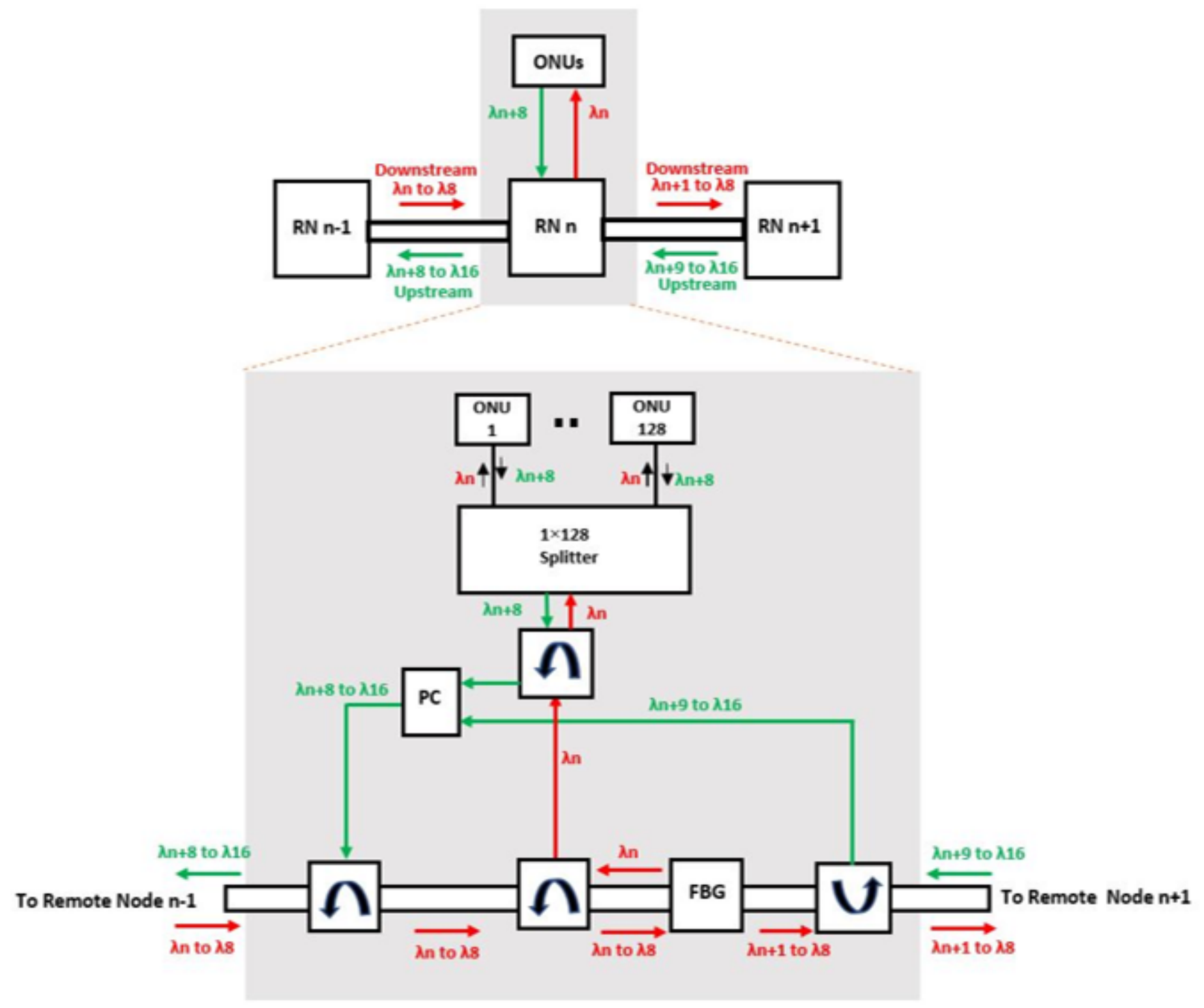

Figure 3

Design of FBG based nth Remote Node for Bus Topology in NGPON-2 


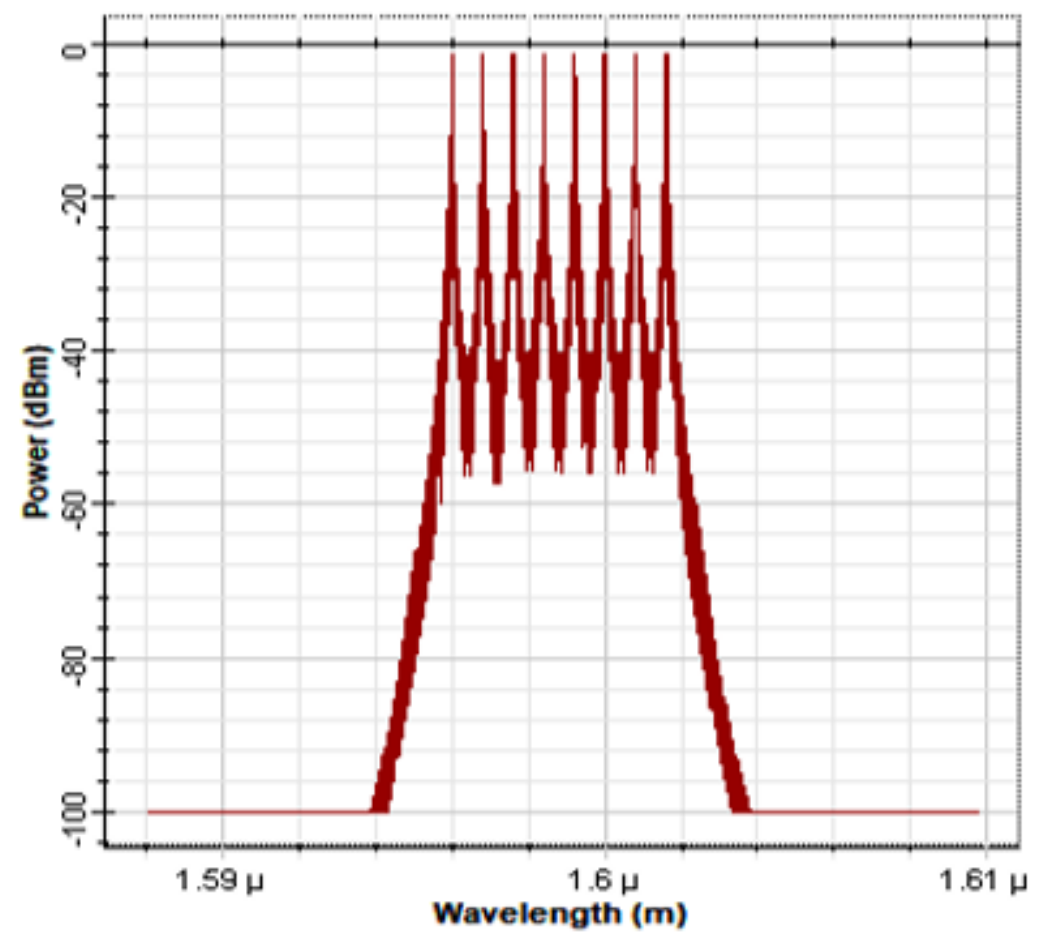

Figure 4

Transmitted downstream signal spectrum from the OLT

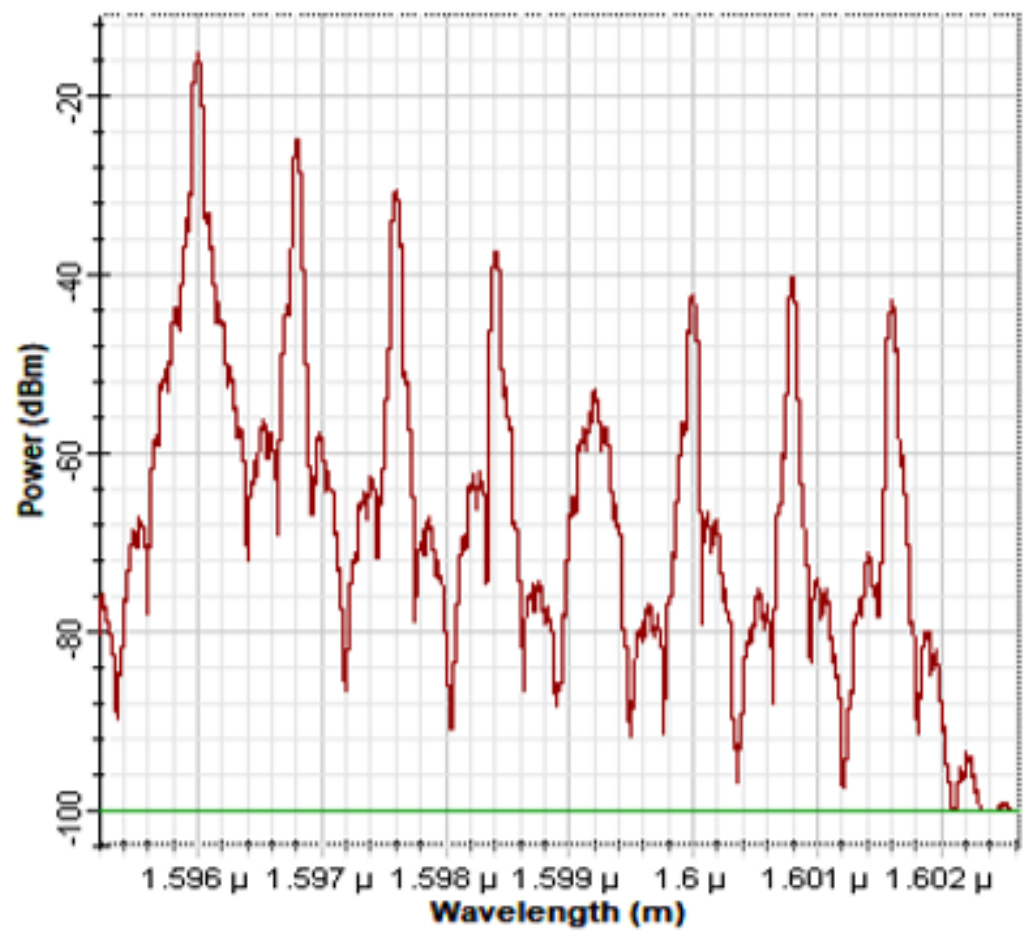

Figure 5

Optical spectrum received at the ONU connected to RN1 


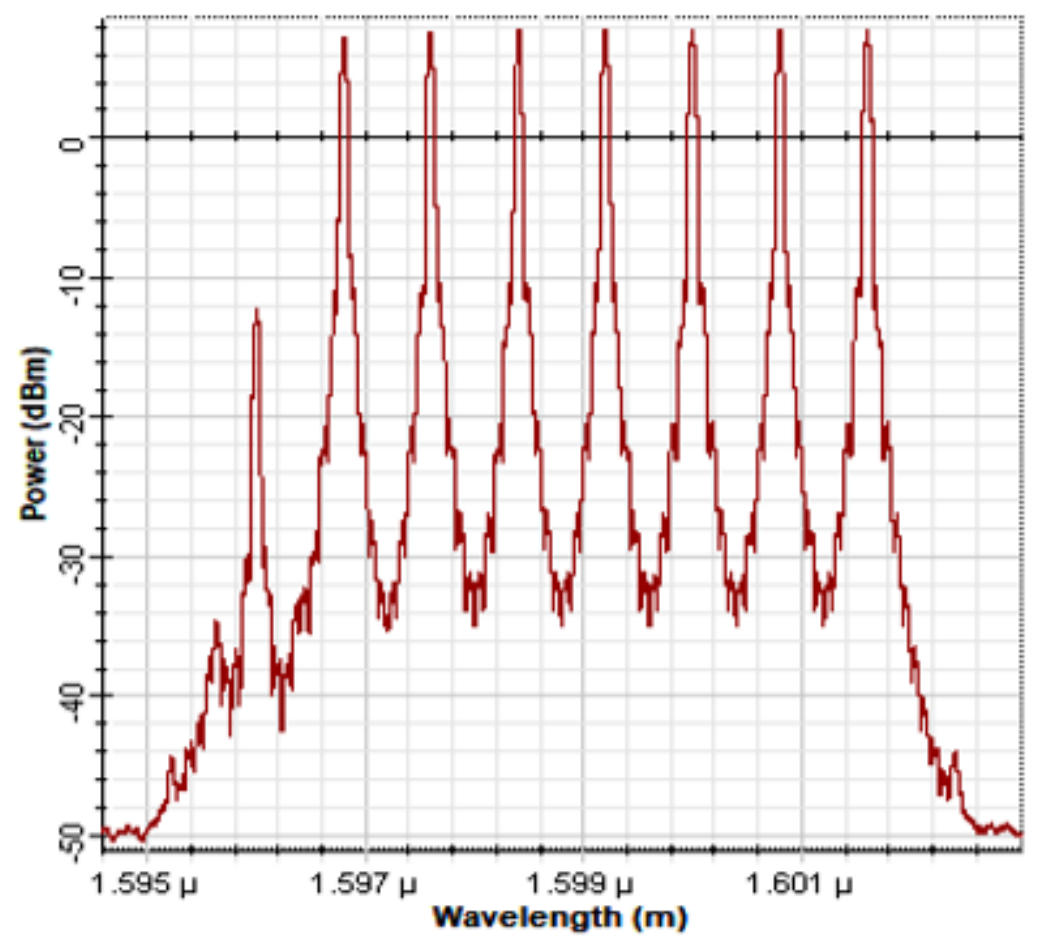

Figure 6

Optical spectrum of downstream signal reached the input of RN2

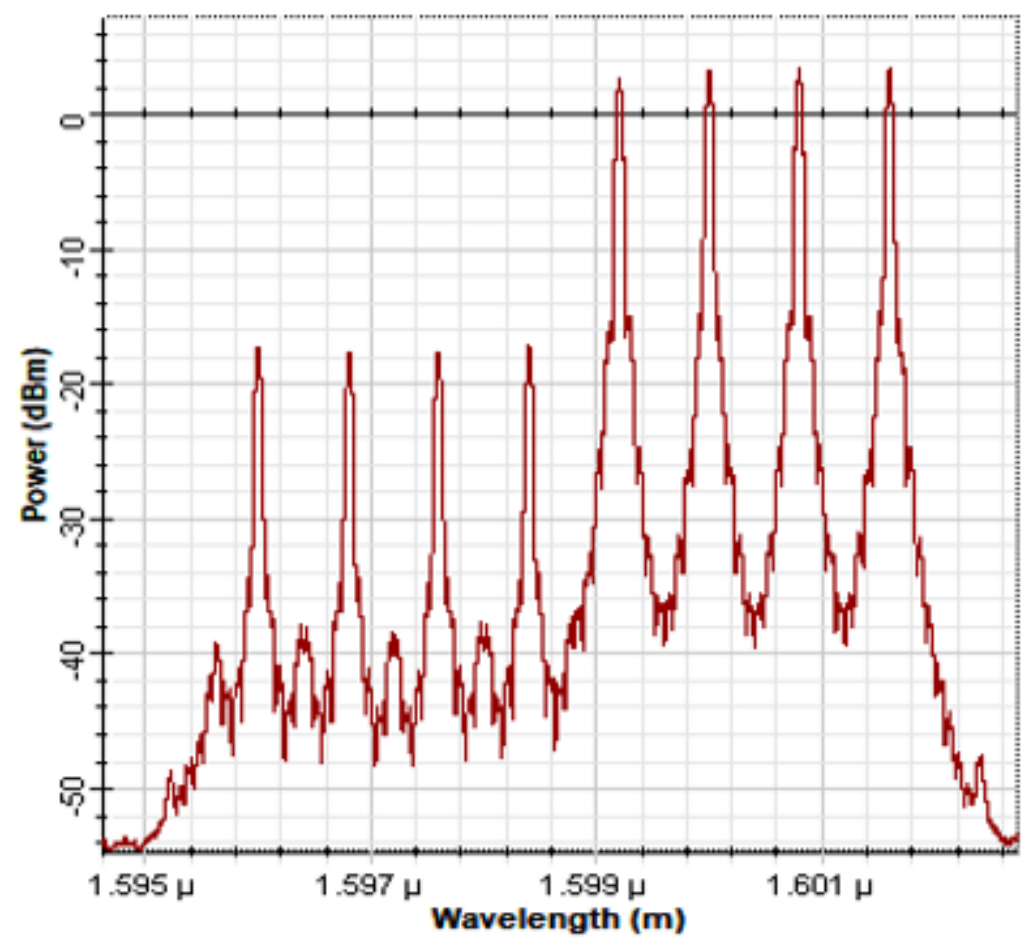

Figure 7

Optical spectrum at the input of RN5 


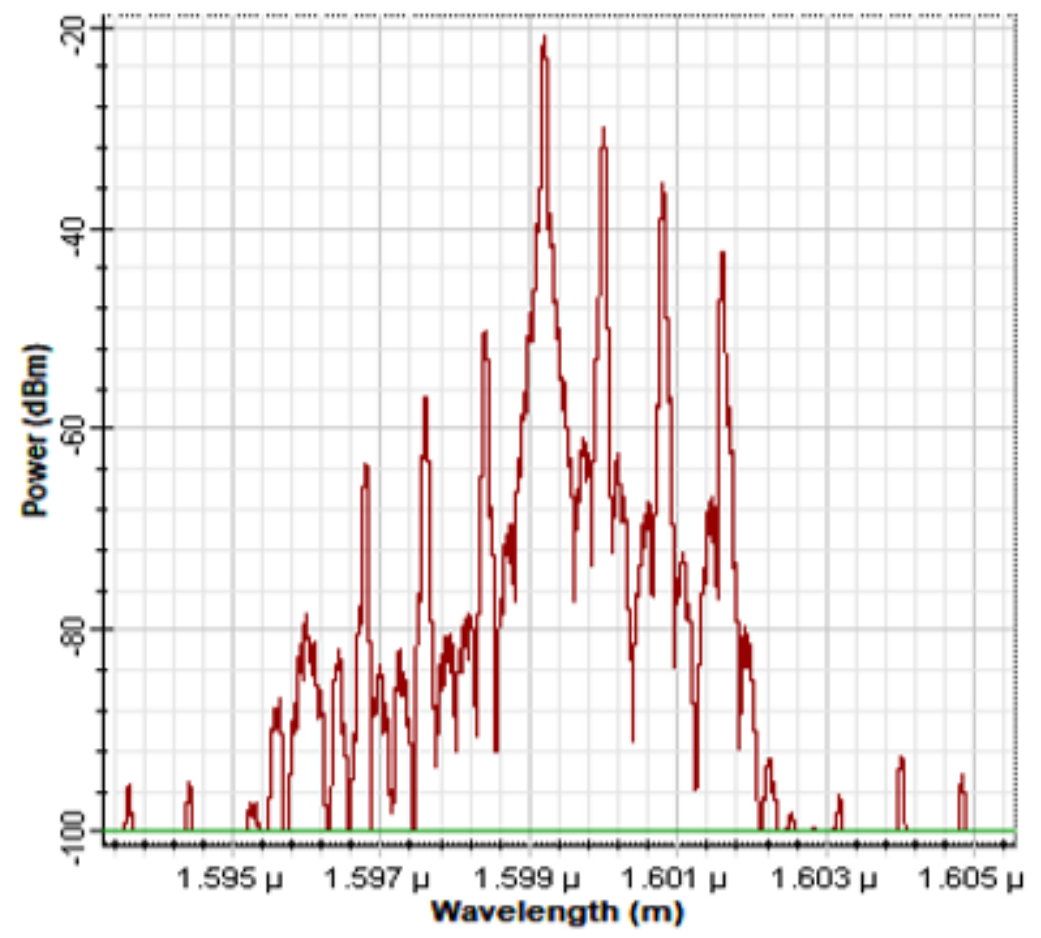

Figure 8

Optical spectrum received at the ONU connected to RN5

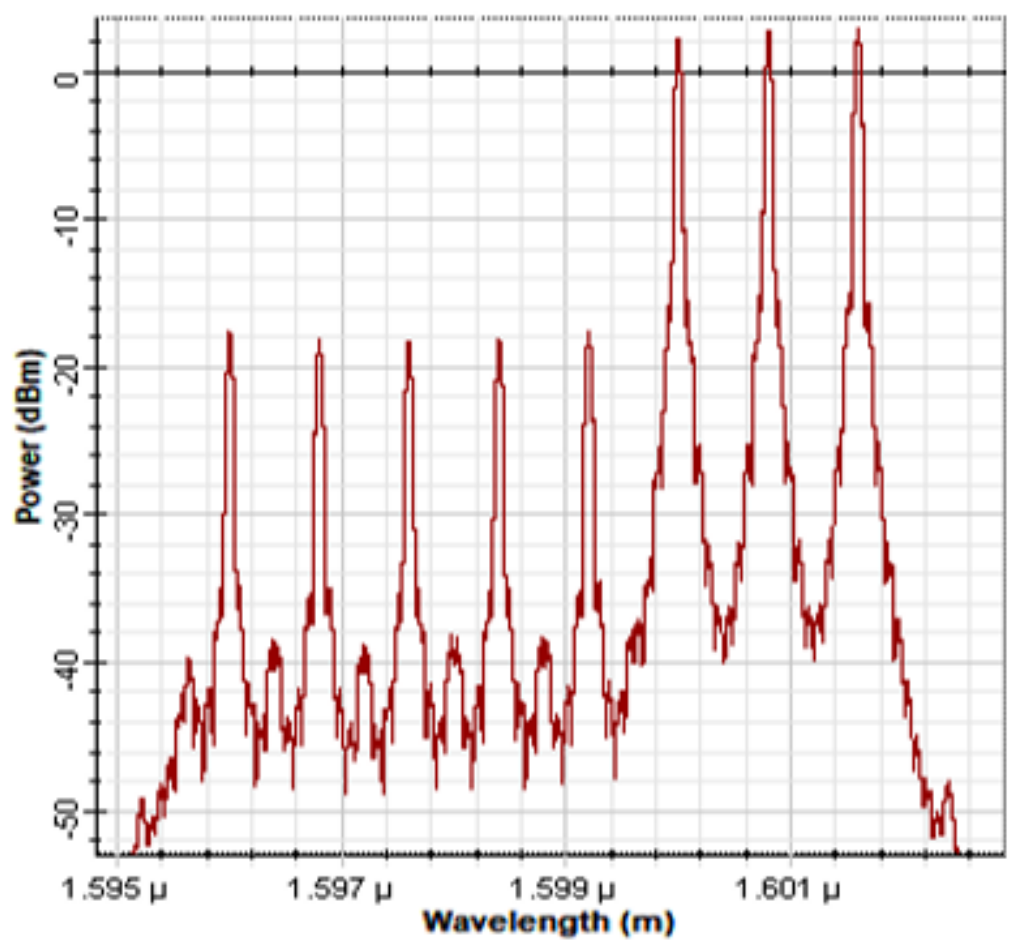

Figure 9

Optical spectrum at the input of RN6 


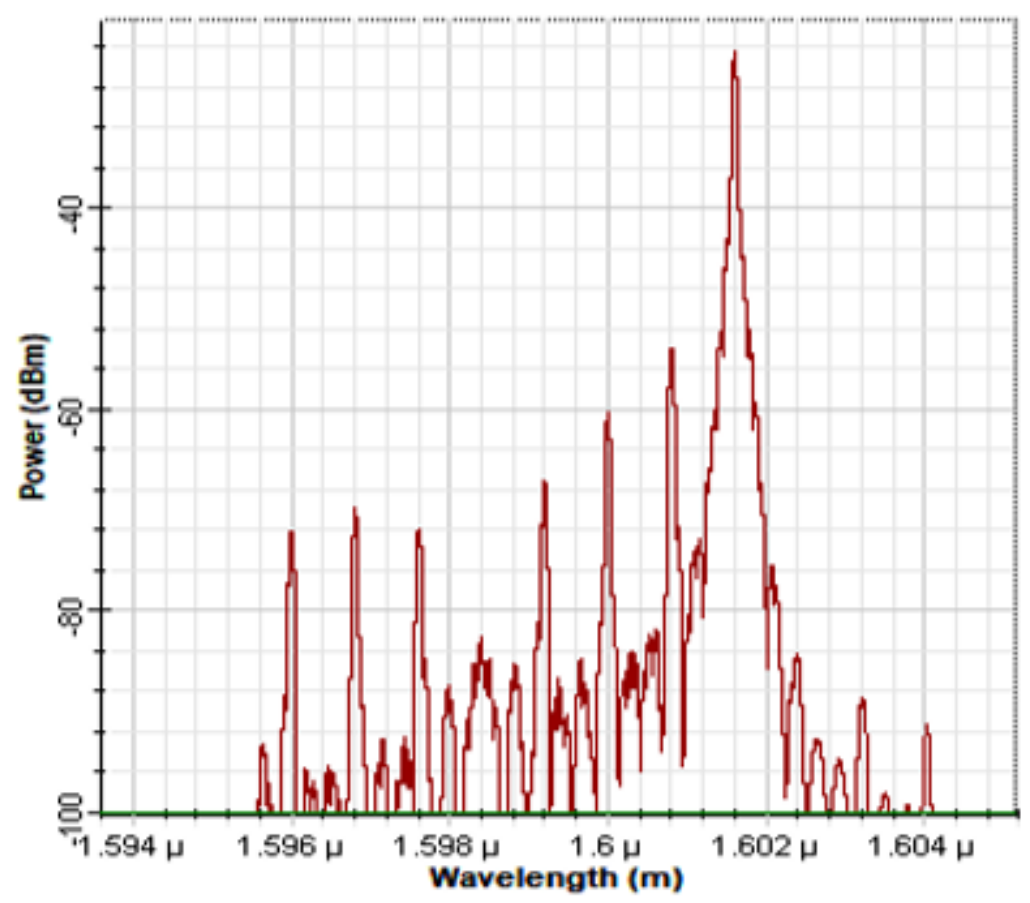

Figure 10

Optical spectrum received at the ONU connected to RN8

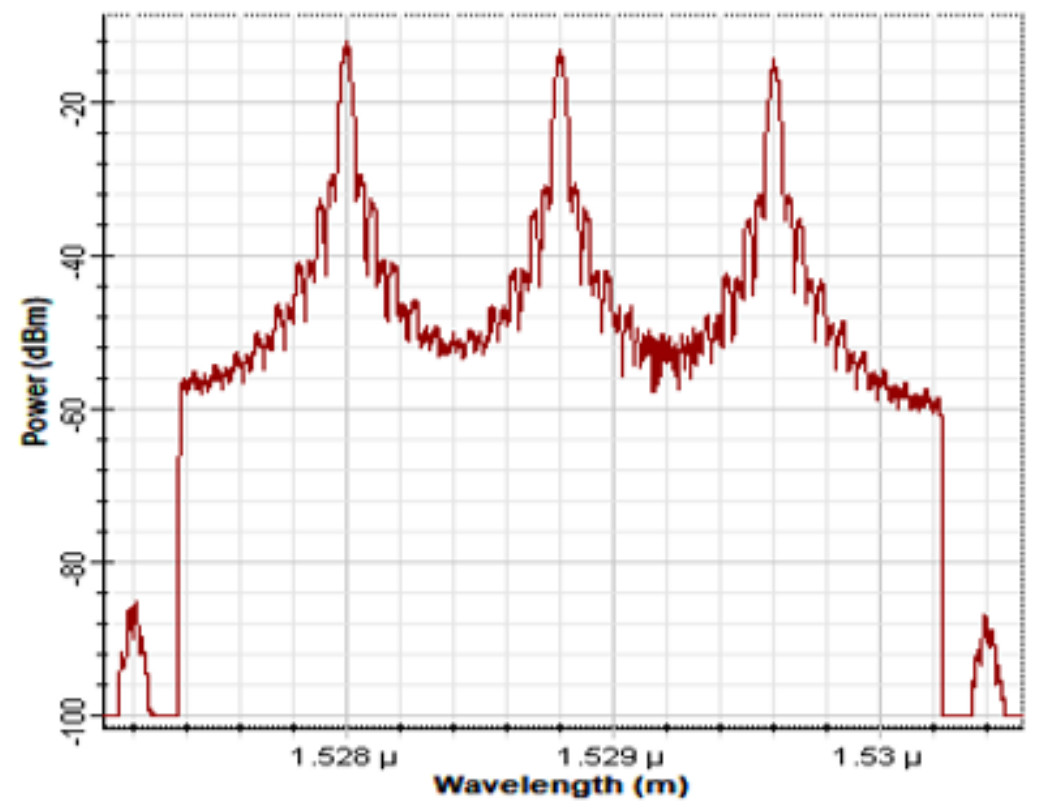

Figure 11

Optical spectrum of the upstream signal received by RN5 from RN6 


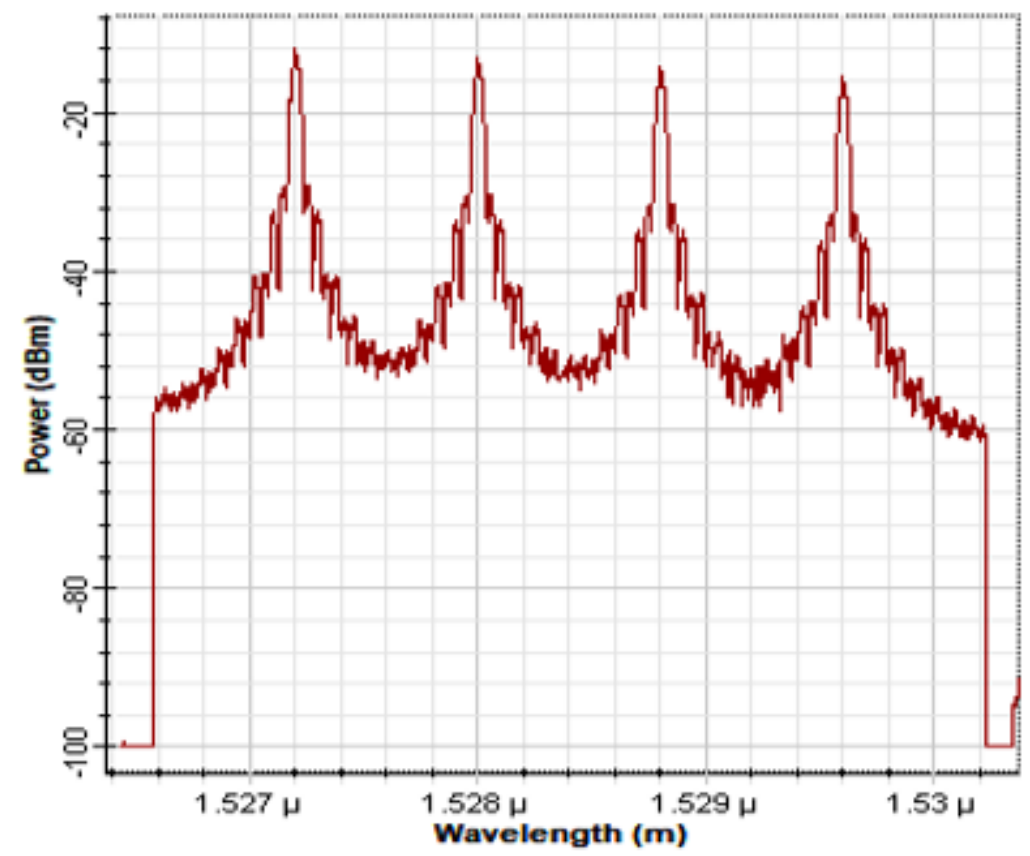

Figure 12

Optical spectrum of the upstream signal Sent by RN5 to RN4

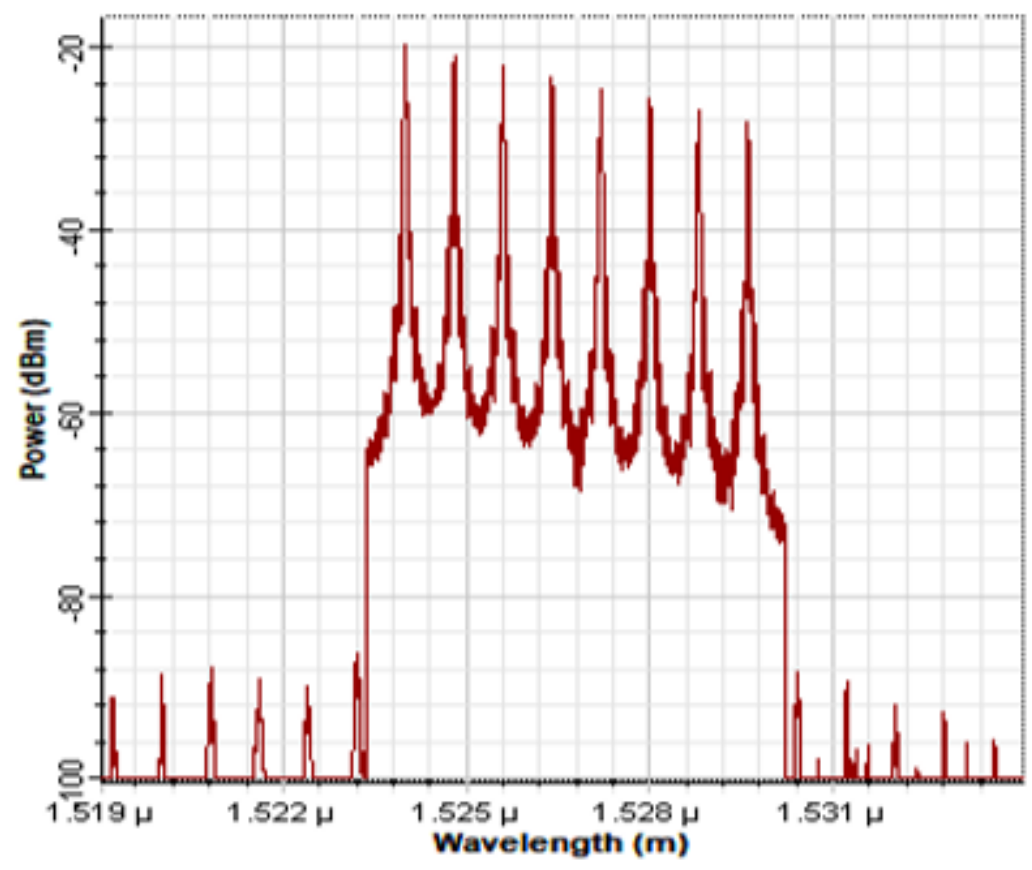

Figure 13

Optical spectrum of the upstream signal received at OLT 


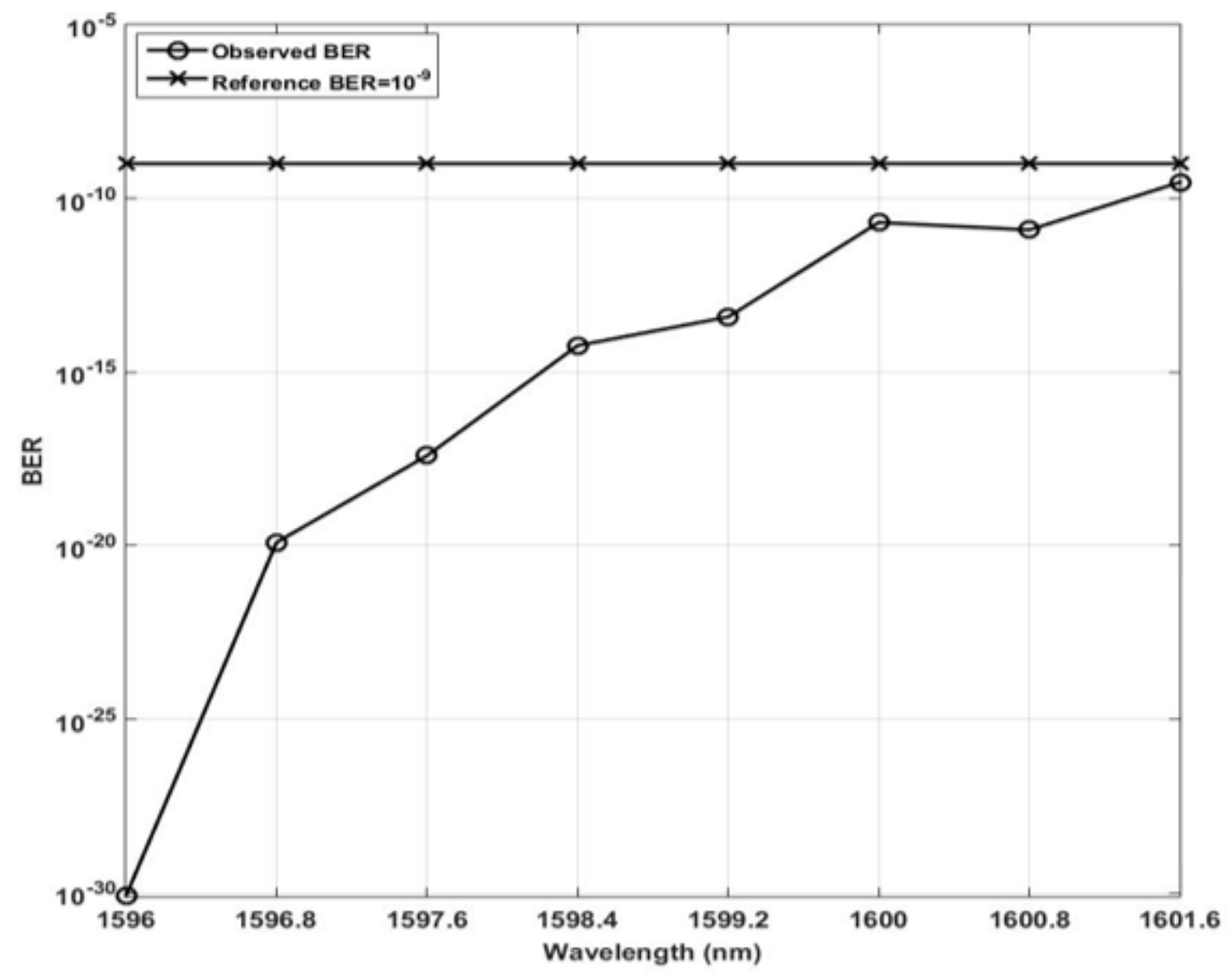

Figure 14

BER at All RNs for Downstream in Bus Topology using FBG 
RN1

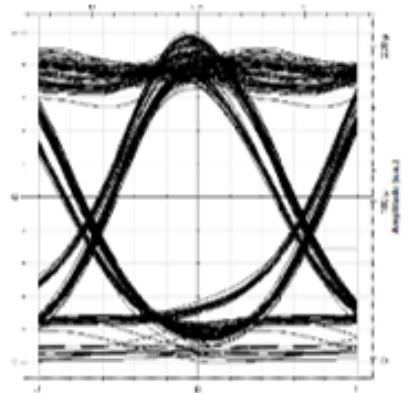

RN5

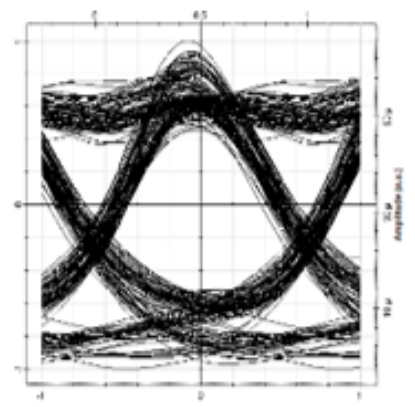

RN2

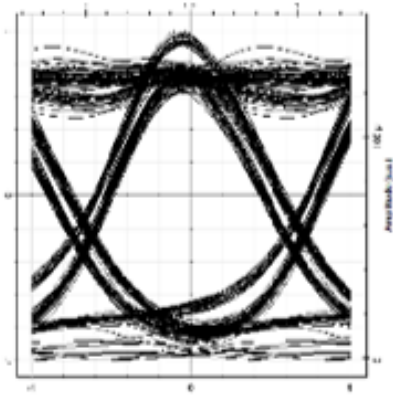

RN6

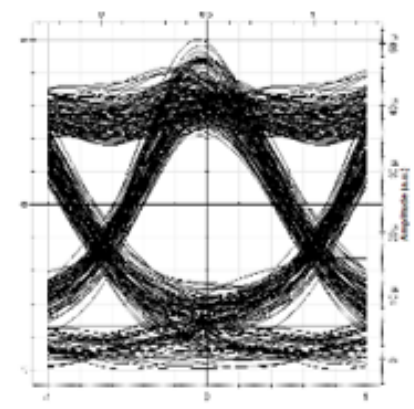

RN3

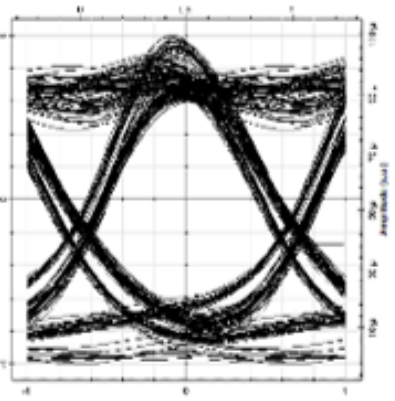

RN7

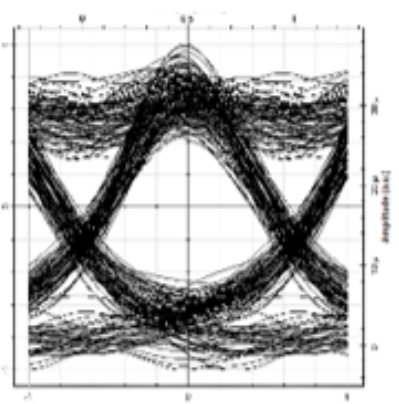

RN4

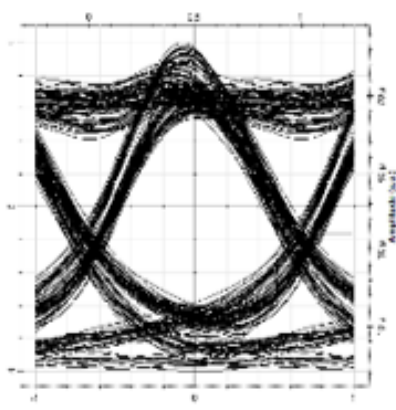

RN8

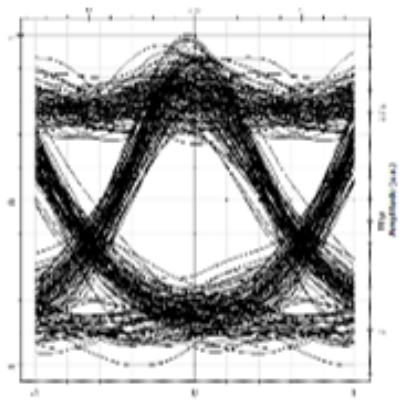

Figure 15

Eye diagrams for the ONUs connected to different remote nodes

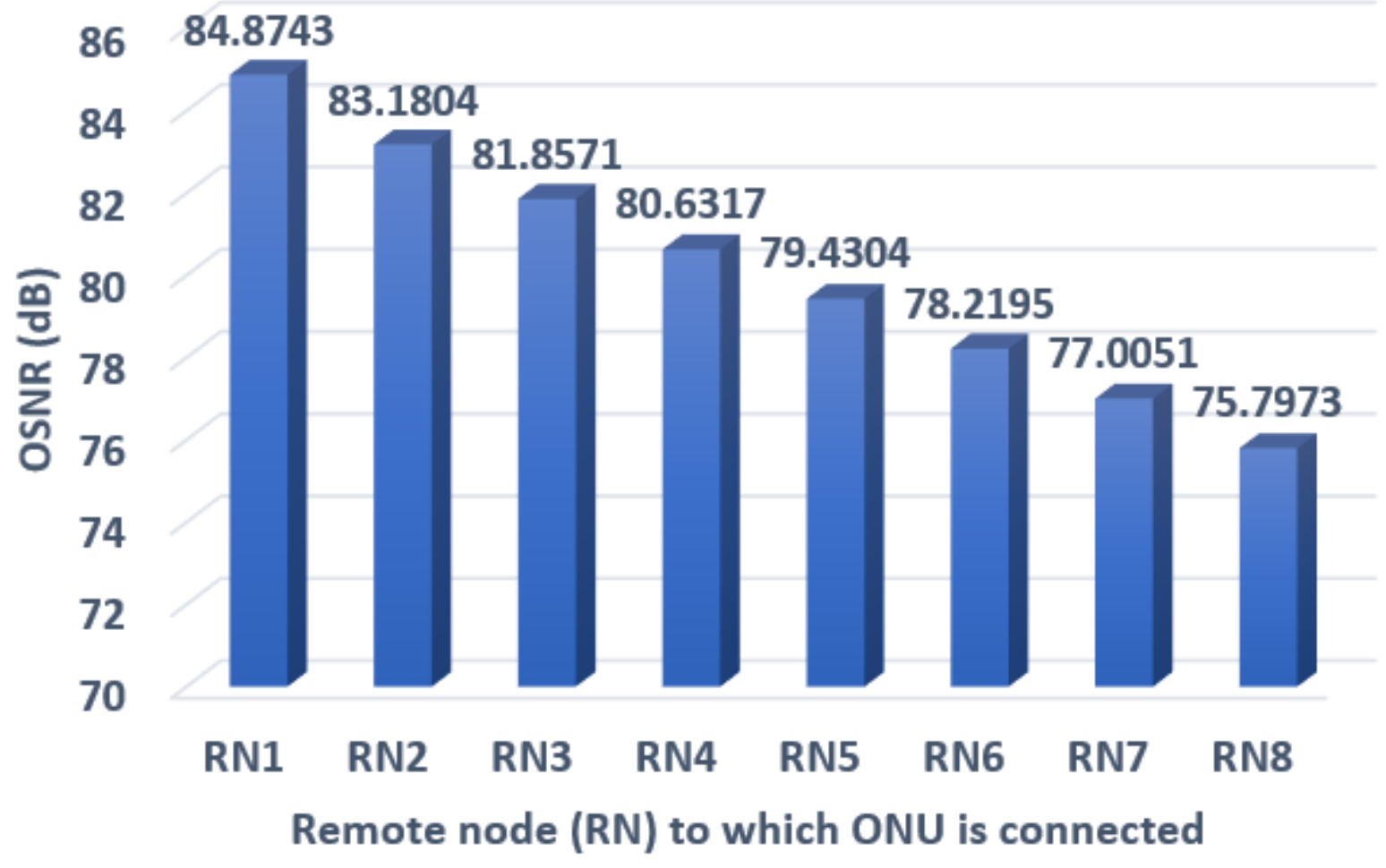


Figure 16

OSNR vs Location of ONU in the system

\section{Image not available with this version}

Figure 17

\section{Image not available with this version}

Figure 18

Image not available with this version

Figure 19 


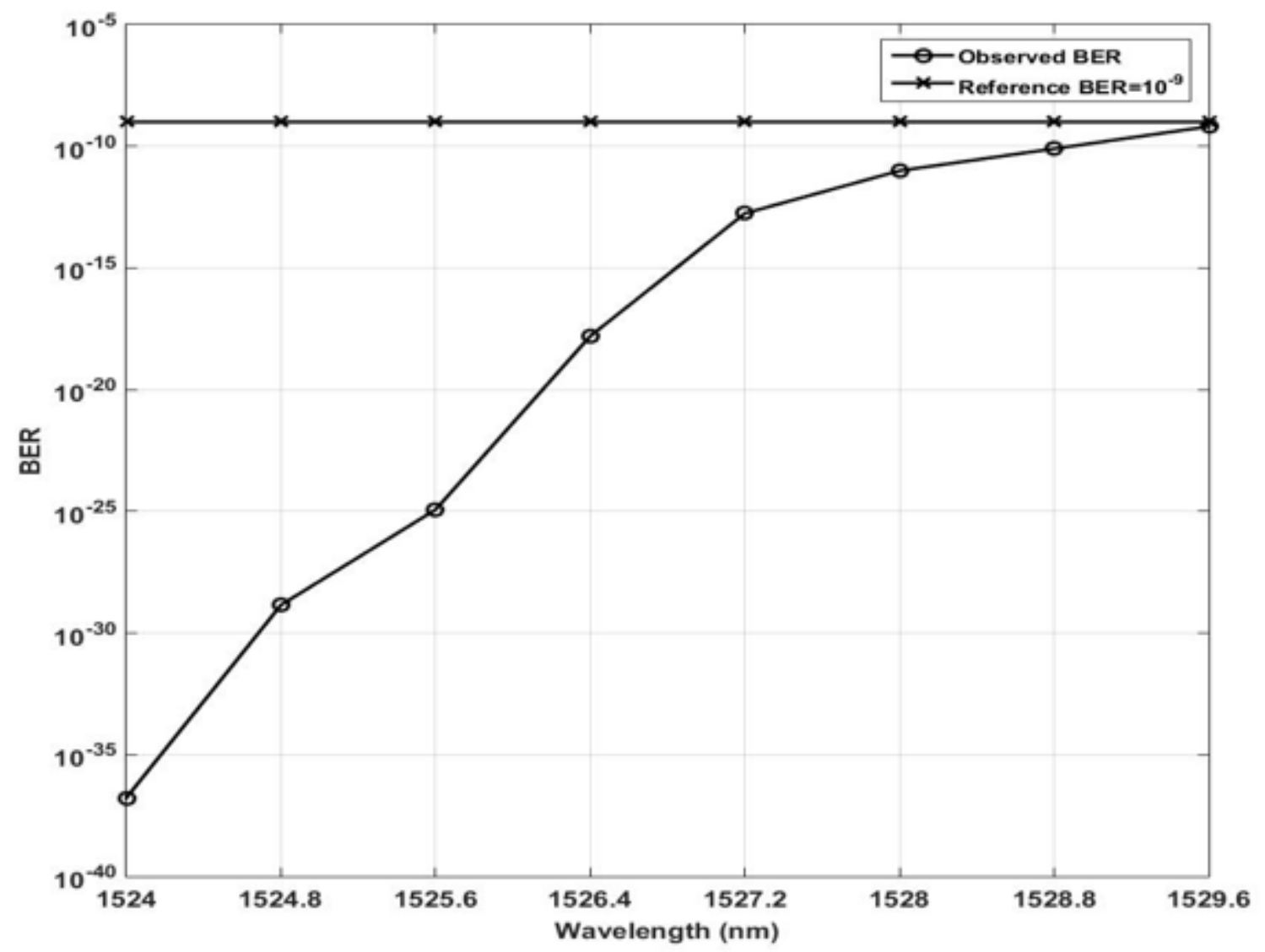

Figure 20

BER observed for the upstream signals coming from all RNs at OLT 